Access to this work was provided by the University of Maryland, Baltimore County (UMBC)

ScholarWorks@UMBC digital repository on the Maryland Shared Open Access (MD-SOAR) platform.

Please provide feedback

Please support the ScholarWorks@UMBC repository by emailing scholarworks-group@umbc.edu and telling us what having access to this work means to you and why it's important to you. Thank you. 


\title{
The Wisdom of Crowds and Transfer Market Values
}

\author{
Dennis Coates \\ Department of Economics, UMBC, Baltimore, MD 21250; coates@umbc.edu \\ National Research University Higher School of Economics. International laboratory of \\ intangible-driven economy \\ Corresponding author
}

Petr Parshakov

National Research University Higher School of Economics. International laboratory of intangible-driven economy. E-mail: pparshakov@hse.ru

\begin{abstract}
Crowd-sourcing of information has become popular in the years since James Surowiecki published The Wisdom of Crowds: why the many are smarter than the few and how collective wisdom shapes business, economies, societies, and nations. In sports, crowd-sourced estimates of players' values and abilities are common, particularly in football where salary information is generally unavailable. The analysis here first considers the characteristics of a good crowd-sourced value then turns to an empirical analysis which applies those characteristics and their implications to assess the quality of the commonly used crowdsourced values from Transfermarkt. Our empirical results show systematic influences from some obvious factors indicating that the crowd-sourced transfer fees are biased as predictors of the true market determined fees. The findings are useful because they address the question of whether these values can reasonably be used as proxies for unknown salary in academic research. Additionally, because Transfermarkt values are often used in negotiations between clubs and players, it is useful to both parties to know the accuracy and the bias of the crowd-sourced values.

Keywords: Forecasting; Decision Support, Wisdom of Crowds; Football; Transfermarkt, FIFA video game

Acknowledgements: The authors thank Tim Pawlowski, Qi Ge, John Solow, Bernd Frick and Brad Humphreys for comments on earlier versions of the paper. This paper is an output of a research project implemented as part of the Basic Research Program at the National Research University Higher School of Economics (NRU HSE).
\end{abstract}


An important advantage in the study of sports is the availability of an enormous amount of data. In every game or match, numerous events are recorded which identify the player and his or her actions. Unlike most other workers, the contribution of every player in a match can be linked to the production of his or her team. When the player's compensation is known, this combination of performance and pay enables testing theories about the workplace that cannot be tested in any other industry. Unfortunately, for the most popular sport in the world, football (soccer), in its richest market, Europe, player contracts are rarely observed, so player compensation is unknown. Not knowing player pay makes it difficult to study the market for players' labor.

An approach to addressing the lack of player pay data in European football is to use crowd-sourced estimates of the value of players to clubs; the best known of these is from transfermarkt.de and is known as the transfer market value. The impetus to crowd-sourcing is the ability to get input from a many people quite quickly at relatively low cost, especially afforded by the internet. Of course, the use of crowd-sourcing is only justified if the information it provides is a good predictor of the unmeasured, unreported or uncertain outcome of interest.

The literature on crowd-sourcing has grown substantially since its beginnings in 1907, when Sir Francis Galton assessed peoples' judgement of the weight of an ox. Summarizing and synthesizing academic research from a variety of fields, James Surowiecki's The Wisdom of Crowds: why the many are smarter than the few and how collective wisdom shapes business, economies, societies, and nations (Surowiecki, 2004) describes the circumstances when a group's information and knowledge are better or more accurate than that of an individual. Key circumstances for groups to improve upon the knowledge and information of any individual are that the individuals within the group have diverse perspectives and that the individuals provide their assessments independently. These individual assessments must then be aggregated in some fashion, while "(e)xtensive research in the forecasting, decision making, and groups literatures has confirmed that averaging is a powerful and robust way of reducing error in quantitative judgment (Larrick \& Soll, 2006)."

The object of this research is to examine crowd-sourced estimates of players' values and abilities. The results will be of interest to both sports economists who wish to understand the market for playing talent and to anyone using crowd-sourcing to make predictions or forecasts, including football clubs, and players and their agents. The first purpose of this research is to determine whether readily available information can be used to improve the ability to predict actual transfer fees relative to the existing crowdsourced values. Knowing the properties of these estimates can be important for the literature that uses crowd-sourced values as a proxy for player compensation. Indeed, the second purpose is to determine if

${ }^{1}$ Citations from the quote have been dropped to enhance readability. 
bias exists in the Transfermarkt values and, if so, if there are identifiable sources or patterns to the bias. The forecasting literature (Davis-Stober, Budescu, Broomell, \& Dana, 2015; Lamberson \& Page, 2012) focuses on minimizing the variance of a crowd sourced forecast, but has paid little attention to the potential bias in those forecasts. A tightly focused forecast that does not include the actual value of the variable being forecast may be less valuable than a less accurate, that is, larger variance, forecast that does engulf the true value of the variable.

The argument is laid out in three steps. In the first step, the transfer market for football players and the sports economics literature studying it are described. The second step discusses the optimal crowdsourcing literature. The third step lays out the hypotheses, the data and the empirical analysis. The paper ends with a discussion of the results and concluding thoughts.

\section{Transfer markets and crowd-sourcing}

In football, clubs can sell the rights to a player to other clubs in exchange for a fee. It is often argued that player values can be approximated by the value of this transfer fee. While such transfers are commonplace, some players are never transferred from one club to another this way and, of course, not all players are transferred each year. Consequently, there is no observable market-determined value for each player in every season. There is, however, a crowd sourced value of every player produced and reported regularly at transfermarkt.co.uk (for the English language version) or transfermarkt.de (for the German language version). The German magazine Kicker also reports estimates of player market values, though the figures are limited to players active in the German league. In addition, video game manufacturers use crowd-sourcing to evaluate the skills of live soccer players for modeling that player's production for the game.

To be clear about the process, in the case of the Transfermarkt values, note that members of the transfermarkt group make predictions about the transfer value of many players each year, far more in fact than are transferred in a season. The values submitted by members of transfermarkt, which is free to join, go through layers of assessments before the ultimate production of the value that gets reported. The process

of assessment is only generally described, but boils down to scrutiny of the reports by established members for plausibility and reliability. Only in a relatively small number of cases are the true values revealed, that is, are players whose values have been predicted by the transfermarkt group actually transferred for a fee. Nonetheless, these guestimates and those of the staff of Kicker magazine are commonly used.

Numerous examples exist of crowd-sourced market values of football players being used as a proxy for the true value of the players. Franck and Nuesch (2012), Haas, Kocher, and Sutter (2004) and Torgler and Schmidt (2007) use the market values published by Kicker magazine. Bryson, Frick, \& Simmons (2013); Frick (2007); Herm, Callsen-Bracker, \& Kreis (2014); Müller, Simons, \& Weinmann (2017); 
Peeters (2018); Prockl \& Frick (2018) all use transfermarkt.de values. Researchers utilize the crowdsourced values when the purpose is to understand the labor market for football players, often with the Kicker or Transfermarkt values serving as a proxy for the largely unknown salary of the players in European football.

A number of papers examine the factors which determine the actual transfer fee when one club purchases the contract of a player from another club. Carmichael, Forrest, and Simmons (1999), Carmichael and Thomas (1993), Dobson, Gerrard, and Howe (2000), Reilly and Witt (1995) and Speight and Thomas (1997) all estimate models of the determinants of transfer prices. The results are not surprising and those factors that make a transfer fee large also tend to explain both a larger player salary and a greater likelihood of being transferred (Frick, 2007). Better players and star players have higher transfer prices than weaker and less well-known or less highly regarded players. Of course, how better players are identified varies between studies. Dobson et al. (2000) find that transfer fees at the lower levels of English football are largely driven by the same factors as found by Carmichael and Thomas (1993). Reilly and Witt (1995) find that transfer fees of black players are 9\% lower than the fees for otherwise identical white players. Frick (2007) is a good review of the literature before 2007.

More closely related to the purpose of this study are those by Herm, Callsen-Bracker, \& Kreis (2014), Müller, Simons, \& Weinmann (2017), Peeters (2018), and Prockl \& Frick (2018) which evaluate the quality of the crowd-sourced values. For example, Peeters (2018) uses Transfermarkt values aggregated to the team level to predict the outcome of football matches and compares those results to the predictions based on FIFA rankings and ELO ratings. The crowd-sourced values perform better than do the FIFA and ELO scores. ${ }^{2}$

Herm et al. (2014) discuss alternative approaches of data aggregation in crowd-sourcing, highlighting the difference between an integrative approach and a selective approach. The integrative approach is likened to democracy in which each individual's assessment is treated identically. Alternatively, this method can be described as completely anonymous, as the identity, qualifications, and prior participation are all unutilized in the aggregation process. The selective approach, or "judge principle", involves a second layer of evaluation in which some people take account of precisely those bits of information that are unused in the integrative approach. For example, a "judge" may determine that one individual's valuation is more plausible, believable, or accurate than another person's valuation based on the first individual having participated longer or having a record of good evaluations. They suggest that the

\footnotetext{
${ }^{2}$ Frick \& Wicker (2016) conduct a similar exercise comparing the accuracy of predictions made by football experts, former players and coaches, with those of sports economists about season outcomes. Economists' predictions use team wage bills, the football experts use their knowledge and intuition. Actual outcomes are better predicted if both the experts' ratings and the team wage bills are used than if only one is used.
} 
selective model will produce better estimates than the integrative model. In the end, Herm et al. (2014) regress Transfermarkt values for a sample of 338 individuals who played in at least one match during the first half of the 2011/12 season of the German Bundesliga against a list of player and team characteristics taken from the existing literature on player values. In other words, they evaluate whether the crowd-sourced value is influenced by commonly used variables in studies of the labor market for football players. They also compare those Transfermarkt values with observed transfer fees for 67 players transferred during the winter 2011/2012 transfer window. Clearly, the Herm et al. (2014) analysis is hindered by the small sample size. More importantly, having raised interesting questions about integrative and selective crowd-sourcing, they are unable to really address them.

Müller et al. (2017) conduct an analysis similar to Herm et al. (2014) but on a much larger sample; they have over 4000 players in the top five football leagues in Europe over the six season period 2009/10 to $2014 / 15$. The total number of player-year observations is 10,350 . However, only 845 players are actually transferred for a fee in their data. Müller et al. (2017) estimate a model which explains the current Transfermarkt value using the lagged Transfermarkt value, player characteristics, performance and skill metrics, and measures of popularity. The model is then used to predict the value of each player and this value compared to the observed transfer fee for those players who were transferred. The authors also compare the Transfermarkt value to the observed transfer fee. Comparison is done by computing the difference between the observed transfer fee and each of the Transfermarkt value and the forecasted value of the Transfermarkt value based on the estimated model. The root mean squared error and the mean absolute error are computed for each of these differences, with the crowd-sourced, Transfermarkt value, difference having a lower RMSE and MAE than the model by about 3.5\%. However, delving deeper, this comparison indicates that the model does better than the crowd for the lowest 90 percent of transfers but that the Transfermarkt value is better for the very large transfer fees.

The finding that the authors' model and the crowds-sourced values do not perform equally well throughout the transfer value distribution suggests an alternative empirical method may provide some insights. For example, a quantile regression model allows the influence of a given variable to be different at the tenth-, twentieth, or fiftieth-percentile than at the ninetieth-percentile. We utilize quantile regressions below to explore this possibility.

Prockl \& Frick (2018) do not assess the accuracy of the Transfermarkt values as predictors of the actual transfer fees. Rather, they evaluate the Transfermarkt values as proxies for player salary. Major League Soccer, in the United States, is the only football league for which player salaries are known for all players for a large number of seasons. Prockl \& Frick (2018) use data covering the 10 seasons from 2006 through 2015 to investigate the precision of the Transfermarkt values and to understand how crowd wisdom 
emerges, develops and matures. For our purposes, the precision of the Transfermarkt values is all that is relevant. They find a positive and statistically significant correlation of .7 or higher between the natural $\log$ of the Transfermarkt values and the natural log of either base or guaranteed salary of players in MLS. Prockl \& Frick (2018) then estimate "salary" regressions with the same explanatory variables but with each of the log Transfermarkt market values, log of base salary and log of guaranteed salary as the dependent variable. They find that the estimated results are quite similar across all three equations; if a variable is statistically significant in one equation it is nearly always significant in the others. Prockl \& Frick (2018) conclude by saying "our results suggest that player market values generated by the wise crowd on transfermarkt.de are very good proxies of current as well as future player salaries."

None of the papers cited suggests that Transfermarkt values are anything other than a proxy for either player salaries or the actual transfer fee that would be paid by one club to another in exchange for a player's contract. That the variables in question are correlated is not at issue. However, an evaluation of these crowd-sourced variables as good estimates of the truth requires more than that the true values and the crowd-sourced values are correlated. Indeed, finding that the two variables are correlated is not the same thing as finding that the crowd-sourced variable is an unbiased predictor of the other or that it produces a guess of the true value that is better than other means of producing a guess. Moreover, the intuition of the wisdom of crowds suggests that large, diverse crowds who provide independent assessments will produce better guesses of the true value than small, homogenous crowds whose assessments are interdependent. One might suspect, therefore, that combining information from two distinct crowds could produce a better judgement than using the information of just one crowd. However, ultimately, the question is whether the crowd-sourced values have properties that make them useful predictors of the unknown variables which are of interest.

\section{Optimal crowds}

The forecasting and operations research literature addresses the issue of the best composition of a

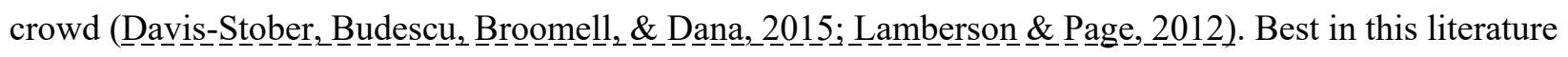
is defined as that which minimizes the mean square (forecast) error. Davis-Stober et al., (2015) builds upon Lamberson \& Page (2012) generalizing that work to allow both for bias in the responses of the crowd members and to allow that which is forecasted to be a random variable. Here the application is to understanding the crowd-sourced valuation of professional football players as done by Transfermarkt or Kicker magazine, or the player ratings as done for EA Sports for that company's FIFA video game. The true value of the player, whether monetary or playing ability, is represented by $V_{p}$ and is assumed to be a

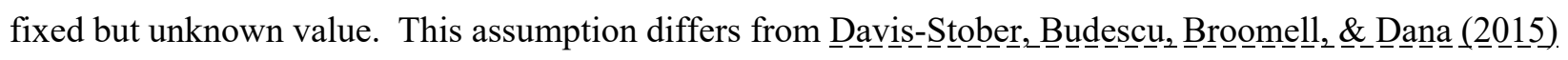




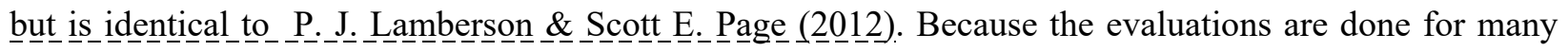
players, the subscript $\mathrm{p}$ makes clear that this is the value of a specific player.

Each of $\mathrm{M}$ individuals sends a signal, forecast or guess, of the player's value, $\mathrm{s}_{\mathrm{ip}}=\mathrm{V}_{\mathrm{p}}+\delta_{\mathrm{ip}}+\varepsilon_{\mathrm{ip}}$. The guess is the true value plus a measure of the bias of the guesser toward this player, $\delta_{\text {ip }}$, plus a completely random component, $\varepsilon_{\mathrm{ip}} . \mathrm{S}_{\mathrm{p}}=\left(\mathrm{s}_{1 \mathrm{p}}, \mathrm{s}_{2 \mathrm{p}}, \ldots, \mathrm{s}_{\mathrm{Mp}}\right)$ simplifies the notation. Diversity in the crowd can be thought of as little or no correlation between the $\delta_{\mathrm{ip}}$ and $\delta_{\mathrm{jp}}$ and between the $\varepsilon_{\mathrm{ip}}$ and $\varepsilon_{\mathrm{jp}}$. The greater the correlations between these idiosyncratic pieces of the guesses, the less diverse the crowd opinions. Likewise, the smaller the correlations, the greater the diversity in the crowd's guesses. Crowd-sourcing also requires that the individual signals are aggregated in some fashion; let $\mathrm{G}\left(\mathrm{S}_{\mathrm{p}}\right)$ be the function that represents this aggregation. A common means of aggregation in the crowd-sourcing literature is averaging. Let $G\left(S_{p}\right)=\sum_{i}^{M} w_{i p} s_{i p}$; that is, the aggregation is the weighted average of the individual signals.

The weighted average of the individual signals produces the true value, in expectation, under certain circumstances. If the weights are constants, $\mathrm{w}_{\mathrm{ip}}$ that sum to one, and $0 \leq \mathrm{w}_{\mathrm{ip}} \leq 1$, and both the random component, $\varepsilon_{\mathrm{ip}}$, and the bias, $\delta_{\mathrm{ip}}$, have a mean of zero in expectation, then the aggregation by weighted average produces the true value of the player, in expectation. Alternatively, if the weights sum to 1 and are independent of the bias and random components, $\mathrm{E}\left(\sum \mathrm{w}_{\mathrm{ip}} \delta_{\mathrm{ip}}\right)=\mathrm{E}\left(\sum \mathrm{w}_{\mathrm{ip}} \varepsilon_{\mathrm{ip}}\right)=0$, the expected value of the weighted average is the true player value.

$$
\begin{aligned}
E\left(\sum_{i}^{M} w_{i p} s_{i p}\right) & =E\left(\sum_{i}^{M} w_{i p}\left(V_{p}+\delta_{i p}+\varepsilon_{i p}\right)\right) \\
& =V_{p} E\left(\sum_{i}^{M} w_{i p}\right)+E\left(\sum_{i}^{M} w_{i p} \delta_{i p}\right)+E\left(\sum_{i}^{M} w_{i p} \varepsilon_{i p}\right)=V_{p}
\end{aligned}
$$

Of course, if the weights are not independent of $S_{p}$, then the weighted average produces a biased estimate of the true value $V_{p}$. Specifically, the bias in the estimator is the difference between the true value and the correlation between the weights and the random error and the individuals' idiosyncratic dislike or like of the player:

$$
\operatorname{bias}\left\{\left(\sum_{i}^{M} w_{i p} s_{i p}\right)\right\}=V_{p}-\left[E\left(\sum_{i}^{M} w_{i p} \delta_{i p}\right)+E\left(\sum_{i}^{M} w_{i p} \varepsilon_{i p}\right)\right]
$$

Transfermarkt's description of its evaluation process makes it clear that there are arbiters whose role it is to evaluate the importance, plausibility or accuracy of the guesses by the people in $\mathrm{M}$; in other words, there are people who determine the weights to apply to individual guesses based on judgements 
about those guesses. Therefore, the weights used by Transfermarkt are conditional on the signals, that is, in general, $\left[E\left(\sum_{i}^{M} w_{i p} \delta_{i p}\right)+E\left(\sum_{i}^{M} w_{i p} \varepsilon_{i p}\right)\right] \neq 0$, so that the final Transfermarkt valuations of the players are biased; on average the Transfermarkt values do not represent the true value of the player, and this is because of the method of construction.

Biased crowd-sourced estimates may be less concerning if the bias is small and the accuracy is high. ${ }^{3}$ Accuracy in crowd-sourced forecasts is often measured by either the root mean squared error, the

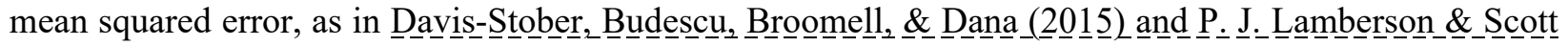
E. Page,_(2012), or as the absolute error or absolute percentage error (Mannes et al., 2014), and weights can be selected for the individual signals to minimize the these measures of error variance. Nonetheless, as a football manager or a player agent who may use the Transfermarkt values in negotiations, it is important to know if these values tend to be higher than or lower than the true worth of the player. Moreover, there is no way to know if Transfermarkt's weights improve on the accuracy of a simple average of the signals sent by the individual members, to say nothing of whether Transfermarkt has selected the optimal weights. Müller et al. (2017) tested their model against the Transfermarkt values, finding it to be an improvement.

\section{Methods and Hypotheses}

The purpose here is to understand the nature of the bias in Transfermakt values as predictors of actual fees paid by one club to another club for the acquisition of a player. To be concrete, take the Transfermarkt value trans as an estimator of the true transfer fee fee. If the Tansfermarkt value is an unbiased estimator of the true market value, then $E(\operatorname{trans}-f e e)=0$. In a sample of players, the difference between the transfer fee and the market value should not be different from zero. More formally, $f e e_{i t}=$ trans $_{i t}+z_{i t}$ and $z_{i t}$ has a mean of zero. In the data we have on over 5000 actual transfers, excluding goal keepers, the mean difference in the fee over the reported transfer value is 244,503 Euros, and a t-test rejects the null of equal means.

We estimate the relationship between the observed transfer fee fee and the Transfermarkt value trans including a variety of covariates $\mathrm{X}$. The set of variables in $\mathrm{X}$ changes, by adding additional covariates, including an alternative crowd-sourced measure of ability, additional variables addressing player ability or stardom, and interaction terms between trans and variables in X.

\footnotetext{
${ }^{3}$ The bias may also be less concerning if the estimates are consistent, meaning the bias disappears and the variance approaches zero as the sample grows larger.
} 


$$
f e e_{i t}=a_{0}+a_{1} \text { trans }_{i t}+\sum_{k}^{K} b_{k} X_{k i t}+\epsilon_{i t}
$$

If the Transfermarkt value is an unbiased estimator of the true transfer fee, then the parameters $\mathrm{a}_{0}$ and $b_{k}$ will be zero and $a_{1}$ will equal 1 . This is the first hypothesis to be tested. Hypothesis $1: H_{0}: a_{0}=b_{k}$ $=0$ and $\mathrm{a}_{1}=1, \mathrm{H}_{1}$ : some $\mathrm{a}_{0} \neq 0, \mathrm{~b}_{\mathrm{k}} \neq 0$ or $\mathrm{a}_{1} \neq 1$.

A second corollary hypothesis is that the true fee is proportional to the Transfermarkt value; that $\mathrm{a}_{0}$ $=b_{k}=0$ and $a_{1} \neq 1$. In this case, the Transfermarkt crowd-sourced value is always either greater than or less than the true fee in expectation, but the ratio between the two values is constant. In this case, the Transfermarkt value is, in expectation, an upward or downward biased estimate of the true transfer fee. Hypothesis 2: $a_{1}=$ fee $_{i t} /$ trans $_{i t}, \mathrm{a}_{1} \neq 1$.

Finally, if Hypothesis 1 is rejected, it is important to know what additional factors predict the true fee; that is, what variables belong in or are among those in X. Both club management and players will find this information valuable as they negotiate transfers or player compensation. Performance indicators are natural possibilities. Carmichael and Thomas (1993) argue fees depend upon player ability and the "crowdpulling power" of the transferred player as well as characteristics of the club including its degree of risk aversion.

Of course, the evaluators at Transfermarkt could reasonably be thought to account for player ability and popularity (crowd-pulling power) but it is difficult to imagine how they could include the club's risk aversion. Moreover, the fee is determined by the interests of both the selling and the buying club, but Transfermarkt evaluators cannot know which is the buying club. Player evaluations are done periodically throughout the year, and the website includes rumors about transfers, but there is no clear statement that players whose values are being reconsidered are among those rumored to be the subject of transfer discussions between clubs. A potential means of addressing such issues is club fixed effects. Such effects are, unfortunately, impractical as our data includes 955 clubs that sold a player to another club and 598 clubs that purchased a player from some other club while the many clubs participate in only a single transfer. Because of issues such as these and motivated by the results in Müller et al. (2017) that suggest that the relationship between transfer market values, their model predictions and actual fees differs between low and high value players, we also estimate the relationship using quantile regression and splitting our sample into clubs from the top five leagues, which are the focus of Müller et al. (2017), and all other leagues. 


\section{Data}

We have two crowd-based estimates, one of player value and one of player quality. The first is Transfermarkt estimates of a market value which is supposed to include individual performance, age, future perspective of a player, the current demand for this player and marketing potential of the player (Müller et al., 2017). The second estimate is from the FIFA video game simulator developed by EA Sports. Sherif (2016) and Coates et al. (2018) explain the process of evaluating the skills for the FIFA video game. In the first step of this process, a "network of over 9000 members reviews the player's abilities, watch him play, and help assign him various ratings." As in the Transfermarkt process, in the next stage, this data is reviewed. At EA Sports this is done "by 300 editors, which arrange it into 300 fields and 35 attribute categories." After that EA "uses this feedback in conjunction with its own stats (scoured from other agencies) to determine ratings." Summarizing, from the EA Sports crowd-sourced player evaluations, our data includes the over all rating and ratings in 35 attribute categories.

We concentrate only on those players, which (1) were sold from one club to another at least once and (2) for which we observe the actual transfer price paid. We collect the data from transfermarkt.de for the period from 1996 through 2016. Since Bosman's case had dramatically changed the market, we do not include the earlier transfers. We exclude the transfers which do not fit the criteria above. Finally, the merged data from three datasets consists of 5,818 observations. Among these observations are transfers involving 598 purchasing clubs and 955 selling clubs. Purchasing clubs come from 56 countries, selling clubs from 77 countries. Transfers are made from clubs in 171 different leagues to clubs in 96 distinct leagues. There are 304 goal keepers which are dropped from the analysis. An additional 6 observations are dropped because their minutes of playing time are missing and 1 observation is dropped because the FIFA rating is missing. Table 1 provides descriptive statistics for this sample, omitting the individual attribute ratings from EA Sports to save on space. 
Table 1. Descriptive statistics

Variable

Transfer fee - thousands of euros

Transfermarkt value - thousands of

euros

Goals per minute (Goals missing

dropped)

Goals per minute (Goals missing set to

$0)$

Assists per minute (Assists missing

dropped)

Assists per minute (Assists missing set

to 0 )

Matches

Age

FIFA rating

Midfield

Defense

National team

Top league
Observations Mean

$$
5,513 \quad 3737.526
$$

Std. Dev.

Min

Max

6466.553

0.225

94500

$5,513 \quad 3490.965 \quad 5208.461$

23

63000

4,245

0.0029

0.0030

0.0002

0.0833

5,513

0.0022

0.0029

0.0000

0.0833

3,797

0.0018

0.0015

0.0002

0.0435

5,513

0.0013

0.0015

0.0000

0.0435

5,293

29.426

11.246

1

75

5,513

23.945

3.164

16

36

5,513

70.401

6.549

35

90

5,513

0.309

0.462

0.460

0.493

0.470
$5,513 \quad 0.304$

$5,513 \quad 0.416$

5,513
0.670

0

1

An issue that arises in the sample is that for many players, goals and/or assists are missing. This is evident in Table 1 as goals and assists per minute are reported both for the subset of observations when missing values are dropped and second when missing values are set equal to zero. These variables are missing primarily for players transferred between teams outside the top leagues or for players on teams in lower divisions. Consequently, we estimate the models on subsets of the data that simply take the missing values as given, dropping those observations, and by replacing the missing values with zeros.

The standard deviation of actual price paid is nearly twice the mean, and the standard deviation in the expert estimates is about $50 \%$ larger than its mean. A bit over $40 \%$ of the observations are players who appeared on their country's national team before they were transferred. The average player is just less than 24 years old, participated in 29 games during a season and, for those with non-missing values of goals and/or assists, records about a quarter of a goal and 0.16 of an assist per 90 minutes (the regulation length 
of a game) of playing time. ${ }^{4}$ We have also included a dummy variable for the players which were transferred from or to top level leagues, such us Serie A, English Premier League, $1^{\text {st }}$ Bundesliga, Ligue 1 or La Liga. The share of such players is $67 \%$.

\section{Empirical results}

Table 2 contains the regression results on the sample when observations with goals or assists missing are dropped from the analysis; Table 3 reports results when missing values of goals and assists are set to zero. The Base model presents the results of a univariate regression model with only the Transfermarkt value and an intercept. The second column reports a model with inclusion of some player performance statistics and age, the third column adds in a dummy variable for National team players and its interaction with the transfer value, and the fourth column introduces the EA Sports video game overall player rating and its interaction with national team players. For each regression, the tables report the adjusted R-squared, the Akaike Information Criteria value and the root mean squared error of the regression.

Table 2. Missing goals dropped

\begin{tabular}{|c|c|c|c|c|}
\hline & Base & No FIFA & National Team & FIFA \\
\hline Transfermarkt value & $\begin{array}{l}1.101^{* * *} \\
(32.86)\end{array}$ & $\begin{array}{l}1.110^{* * *} \\
(32.75)\end{array}$ & $\begin{array}{l}1.026^{* * *} \\
(18.34)\end{array}$ & $\begin{array}{l}0.967^{* * *} \\
(14.49)\end{array}$ \\
\hline Matches & & $\begin{array}{l}22.04^{* *} \\
(2.63)\end{array}$ & $\begin{array}{l}14.32 \\
(1.64)\end{array}$ & $\begin{array}{l}16.82 \\
(1.95)\end{array}$ \\
\hline Goals per minute & & $\begin{array}{c}104687.6^{* *} \\
(2.86)\end{array}$ & $\begin{array}{c}91109.5^{*} \\
(2.44)\end{array}$ & $\begin{array}{c}91466.0^{*} \\
(2.48)\end{array}$ \\
\hline Assists per minute & & $\begin{array}{c}-138075.8^{* *} \\
(-3.18)\end{array}$ & $\begin{array}{c}-108709.1^{*} \\
(-2.51)\end{array}$ & $\begin{array}{c}-101473.2^{*} \\
(-2.36)\end{array}$ \\
\hline Age & & $\begin{array}{l}-699.5^{* *} \\
(-2.66)\end{array}$ & $\begin{array}{l}-646.0^{*} \\
(-2.46)\end{array}$ & $\begin{array}{l}-785.2^{* *} \\
(-3.02)\end{array}$ \\
\hline Age squared & & $\begin{array}{l}8.174 \\
(1.58)\end{array}$ & $\begin{array}{l}7.004 \\
(1.35)\end{array}$ & $\begin{array}{l}10.02 \\
(1.95)\end{array}$ \\
\hline National Team & & & $\begin{array}{l}-276.9 \\
(-1.12)\end{array}$ & $\begin{array}{l}10580.8^{* * *} \\
(4.25)\end{array}$ \\
\hline $\begin{array}{l}\text { Transfermarkt } \\
\text { value*National team }\end{array}$ & & & $\begin{array}{c}0.0795 \\
(1.23)\end{array}$ & $\begin{array}{l}0.190^{*} \\
(2.31)\end{array}$ \\
\hline
\end{tabular}




\begin{tabular}{|c|c|c|c|c|}
\hline FIFA rating & & & & $\begin{array}{l}40.97^{*} \\
(2.45)\end{array}$ \\
\hline $\begin{array}{l}\text { National team * FIFA } \\
\text { rating }\end{array}$ & & & & $\begin{array}{c}-155.8^{* * *} \\
(-4.13)\end{array}$ \\
\hline Constant & $\begin{array}{l}-193.9 \\
(-1.61)\end{array}$ & $\begin{array}{l}11148.8^{* * *} \\
(3.42)\end{array}$ & $\begin{array}{c}12682.6^{* * *} \\
(3.95)\end{array}$ & $\begin{array}{c}11461.7^{* * *} \\
\quad(3.47)\end{array}$ \\
\hline $\begin{array}{l}\text { Position dummies } \\
\text { Countries (from and to) } \\
\text { and year dummies }\end{array}$ & $\begin{array}{l}\text { No } \\
\text { No }\end{array}$ & $\begin{array}{l}\text { Yes } \\
\text { No }\end{array}$ & $\begin{array}{l}\text { Yes } \\
\text { Yes }\end{array}$ & $\begin{array}{l}\text { Yes } \\
\text { Yes }\end{array}$ \\
\hline $\begin{array}{l}N \\
\text { adj. } R^{2} \\
\text { AIC } \\
\text { RMSE }\end{array}$ & $\begin{array}{c}3324 \\
0.783 \\
63814.0 \\
3567.9\end{array}$ & $\begin{array}{c}3324 \\
0.797 \\
63595.5 \\
3448.9\end{array}$ & $\begin{array}{c}3324 \\
0.807 \\
63507.4 \\
3360.0\end{array}$ & $\begin{array}{c}3324 \\
0.809 \\
63473.6 \\
3342.0\end{array}$ \\
\hline
\end{tabular}

Table 3. Missing goals set to zero

\begin{tabular}{|c|c|c|c|c|}
\hline & Base & No FIFA & National Team & FIFA \\
\hline Transfermarkt value & $\begin{array}{l}1.095^{* * *} \\
(36.57)\end{array}$ & $\begin{array}{l}1.110^{* * *} \\
(36.23)\end{array}$ & $\begin{array}{l}1.054^{* * *} \\
(23.33)\end{array}$ & $\begin{array}{l}1.010^{* * *} \\
(19.25)\end{array}$ \\
\hline Matches & & $\begin{array}{l}15.61^{* * *} \\
(3.44)\end{array}$ & $\begin{array}{l}11.83^{* *} \\
(2.65)\end{array}$ & $\begin{array}{l}12.96^{* *} \\
(2.97)\end{array}$ \\
\hline Goals per minute & & $\begin{array}{l}41114.3^{*} \\
\quad(2.36)\end{array}$ & $\begin{array}{l}45070.2^{*} \\
(2.55)\end{array}$ & $\begin{array}{c}44316.7^{*} \\
(2.55)\end{array}$ \\
\hline Assists per minute & & $\begin{array}{c}-97227.0^{* * *} \\
(-3.30)\end{array}$ & $\begin{array}{c}-64576.2^{*} \\
(-2.15)\end{array}$ & $\begin{array}{c}-60222.2^{*} \\
(-2.02)\end{array}$ \\
\hline Age & & $\begin{array}{l}-473.1^{* *} \\
(-2.70)\end{array}$ & $\begin{array}{l}-367.2^{*} \\
(-2.10)\end{array}$ & $\begin{array}{l}-490.7^{* *} \\
(-2.79)\end{array}$ \\
\hline Age squared & & $\begin{array}{l}4.426 \\
(1.27)\end{array}$ & $\begin{array}{l}2.151 \\
(0.62)\end{array}$ & $\begin{array}{l}4.830 \\
(1.37)\end{array}$ \\
\hline National Team & & & $\begin{array}{l}-208.7 \\
(-1.12)\end{array}$ & $\begin{array}{c}7953.3^{* * *} \\
(4.30)\end{array}$ \\
\hline $\begin{array}{l}\text { Transfermarkt } \\
\text { value*National team }\end{array}$ & & & 0.0463 & $0.136^{*}$ \\
\hline
\end{tabular}




\begin{tabular}{lcccc} 
National team * FIFA & & & $-117.9^{* * *}$ \\
rating & & & & $(-1.17)$ \\
Constant & -106.8 & $8255.0^{* * *}$ & $8616.3^{* * *}$ & $8163.6^{* * *}$ \\
& $(-1.22)$ & $(3.86)$ & $(4.04)$ & $(3.81)$ \\
& & & & Yes \\
Position dummies & No & Yes & Yes & Yes \\
$\begin{array}{l}\text { Countries (from and to) } \\
\text { and year dummies }\end{array}$ & No & No & Yes & 5293 \\
\hline$N$ & 5293 & 5293 & 5293 & 0.802 \\
adj. $R^{2}$ & 0.774 & 0.789 & 0.800 & 99600.8 \\
AIC & 100191.4 & 99841.8 & 99643.0 & 2921.6 \\
RMSE & 3119.4 & 3016.1 & 2933.8 & \\
\hline
\end{tabular}

$t$ statistics in parentheses

${ }^{*} p<0.05,{ }^{* *} p<0.01,{ }^{* * *} p<0.001$

As one can see from either Table 2 or Table 3, Transfermarkt value is a statistically significant predictor of the actual transfer fee in every specification. Moreover, the coefficient is always larger than 1 indicating that on average the Transfermarkt value is too below the actual fee paid for the player, all other things held constant. In the specifications including the year and to and from country dummy variables, the coefficient on Transfermarkt value is not statistically different from 1, but in the models without the year and to and from country dummies, the Transfermarkt value coefficient is statistically different than 1.

On the other hand, one can easily reject Hypothesis 1, and by extension Hypothesis 2, which implies that Transfermarkt values are not unbiased predictors of actual transfer fees. Readily and easily observed information about players improve the ability to predict the actual transfer fee paid beyond what the Transfermarkt value provides. These variables are information on the players age, his position, whether he had been on his country's National Team, and his goals and assists.

Table 4 limits the sample to clubs from the top leagues, as in Müller et al. (2017). The first two columns use the data dropping observations with missing values for goals and assists, the third and fourth columns replace the missing values with zeros. As before, the Transfermarkt value is statistically significant and the addition of the player age, performance, National Team participation and position dummy variables are jointly statistically significant. As above, the coefficient on Transfermarkt value is statistically different 
from one in the base models, but not different from one in the models with the additional explanatory variables.

Table 4. Top Leagues Only

\begin{tabular}{|c|c|c|c|c|}
\hline & Base & FIFA & Base & FIFA \\
\hline Transfermarkt value & $\begin{array}{l}1.099^{* * *} \\
(29.53)\end{array}$ & $\begin{array}{l}0.941^{* * *} \\
(12.35)\end{array}$ & $\begin{array}{l}1.095^{* * *} \\
(33.30)\end{array}$ & $\begin{array}{l}0.995^{* * *} \\
(16.79)\end{array}$ \\
\hline National Team & & $\begin{array}{l}14408.5^{* * *} \\
(4.27)\end{array}$ & & $\begin{array}{c}10267.6^{* * *} \\
(4.19)\end{array}$ \\
\hline \multirow{2}{*}{$\begin{array}{l}\text { Transfermarkt } \\
\text { value*National team }\end{array}$} & & $0.209^{*}$ & & 0.146 \\
\hline & & $(2.30)$ & & (1.94) \\
\hline FIFA rating & & $\begin{array}{l}60.37^{*} \\
(2.46)\end{array}$ & & $\begin{array}{l}36.14^{*} \\
(2.34)\end{array}$ \\
\hline \multirow{2}{*}{$\begin{array}{l}\text { National team * FIFA } \\
\text { rating }\end{array}$} & & $-207.7^{* * *}$ & & $-149.0^{* * *}$ \\
\hline & & $(-4.19)$ & & $(-4.08)$ \\
\hline Matches & & $\begin{array}{l}20.87 \\
(1.72)\end{array}$ & & $\begin{array}{l}17.96^{* *} \\
(2.94)\end{array}$ \\
\hline Goals per minute & & $\begin{array}{l}123262.2^{*} \\
(2.21)\end{array}$ & & $\begin{array}{l}59362.0^{*} \\
(2.32)\end{array}$ \\
\hline Assists per minute & & $\begin{array}{c}-131250.8^{*} \\
(-2.21)\end{array}$ & & $\begin{array}{c}-80928.8^{*} \\
(-2.04)\end{array}$ \\
\hline Age & & $\begin{array}{c}-1010.3^{* *} \\
(-2.74)\end{array}$ & & $\begin{array}{l}-638.9^{*} \\
(-2.57)\end{array}$ \\
\hline Age squared & & $\begin{array}{l}13.44 \\
(1.86)\end{array}$ & & $\begin{array}{l}6.811 \\
(1.39)\end{array}$ \\
\hline Constant & $\begin{array}{l}-150.5 \\
(-0.86)\end{array}$ & $\begin{array}{c}13987.5^{* *} \\
(3.03)\end{array}$ & $\begin{array}{l}-55.56 \\
(-0.45)\end{array}$ & $\begin{array}{l}10239.6^{* * *} \\
(3.46)\end{array}$ \\
\hline Position dummies & No & Yes & No & Yes \\
\hline $\begin{array}{l}\text { Countries (from and to) } \\
\text { and year dummies }\end{array}$ & No & Yes & No & Yes \\
\hline$N$ & 2242 & 2242 & 3584 & 3584 \\
\hline $\operatorname{adj} . R^{2}$ & 0.768 & 0.802 & 0.764 & 0.798 \\
\hline AIC & 43763.6 & 43490.7 & 68961.1 & 68487.9 \\
\hline RMSE & 4190.4 & 3874.8 & 3646.3 & 3375.1 \\
\hline
\end{tabular}

$t$ statistics in parentheses 
${ }^{*} p<0.05,{ }^{* *} p<0.01,{ }^{* * *} p<0.001$

Table 5 restricts the analysis to the "lesser" leagues. This designation is not meant to denigrate the leagues most of which are from smaller countries or the second or third divisions in their countries. The important finding for our purposes is that the Transfermarkt value is again a biased predictor of the actual fee paid for a player, as participation in his country's National Team, his age and his performance all are statistically significant predictors of fee paid. A second finding is that the Transfermarkt value coefficient is now significantly different from one in the full models but not in the base models. Moreover, those coefficients are far below one, at about 0.67 and 0.71 , indicating that the Transfermarkt far overvalues players from these leagues.

Table 5. Lesser Leagues Only

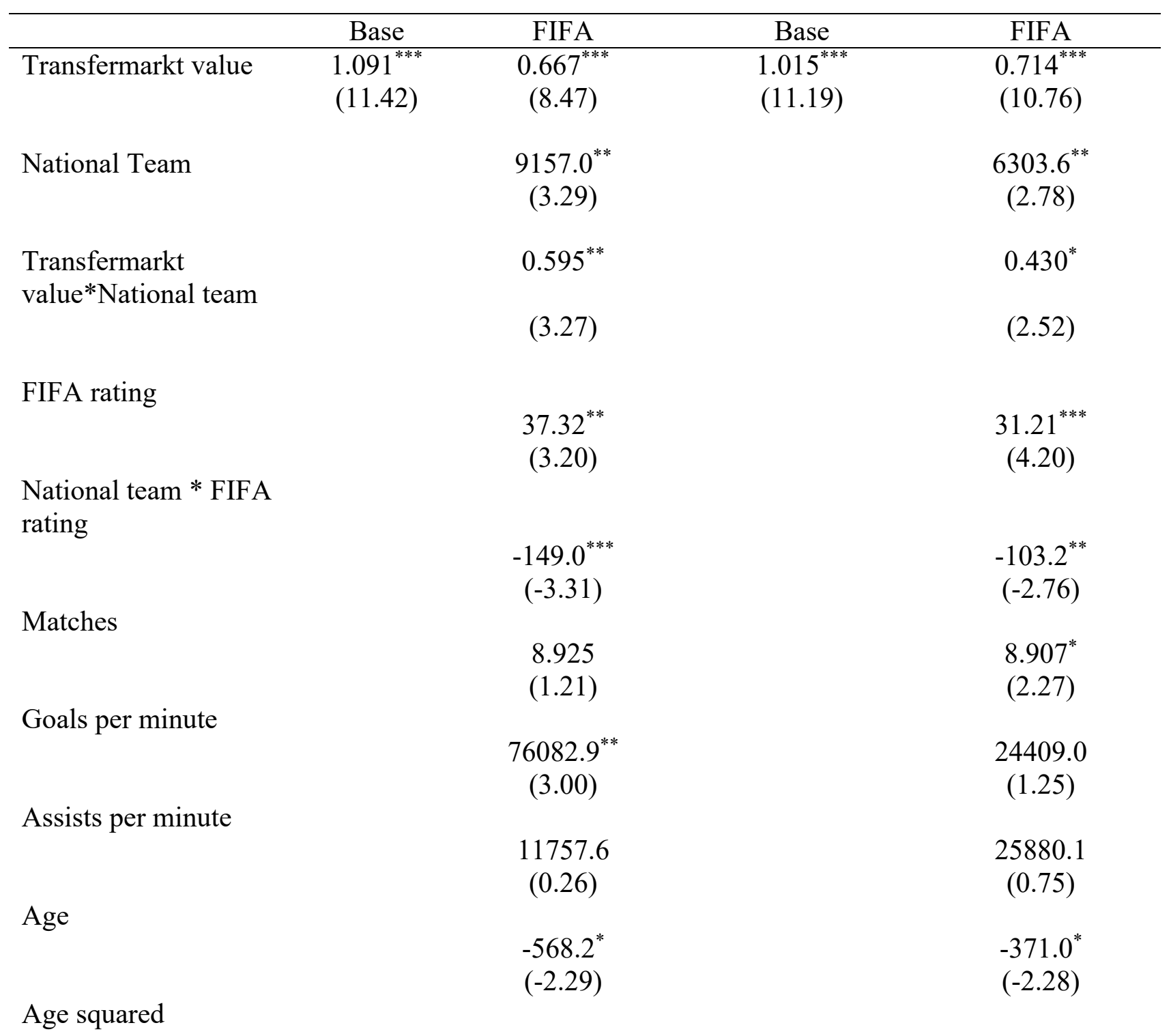




\begin{tabular}{lcccc} 
Constant & -242.0 & $6250.7^{*}$ & -96.24 & $4214.9^{*}$ \\
& $(-1.62)$ & $(2.12)$ & $(-0.80)$ & $(2.21)$ \\
\hline $\begin{array}{l}\text { Position dummies } \\
\text { Countries (from and to) } \\
\text { and year dummies }\end{array}$ & No & Yes & Yo & Yes \\
\hline$N$ & & & & Yos \\
adj. $R^{2}$ & 1082 & 1082 & 1709 & 1709 \\
AIC & 0.722 & 0.777 & 0.684 & 0.733 \\
RMSE & 19107.2 & 18944.7 & 29820.7 & 29615.6 \\
& 1652.0 & 1479.9 & 1487.8 & 1368.4 \\
\hline
\end{tabular}

$t$ statistics in parentheses

${ }^{*} p<0.05,{ }^{* *} p<0.01,{ }^{* * *} p<0.001$

The analysis to this point has indicated that Transfermarkt values can be improved upon using some readily available information and that the relationship between actual fees paid and Transfermarkt values differs between top leagues and "lesser" leagues. Next we use quantile regression to explore the entire distribution of the fees paid rather than just the mean of the distribution. Tables 6-8 present quantile regression results, from the base model, the full model and the full model limited to the top leagues. ${ }^{5}$

Table 6: Quantile Regression - Base model

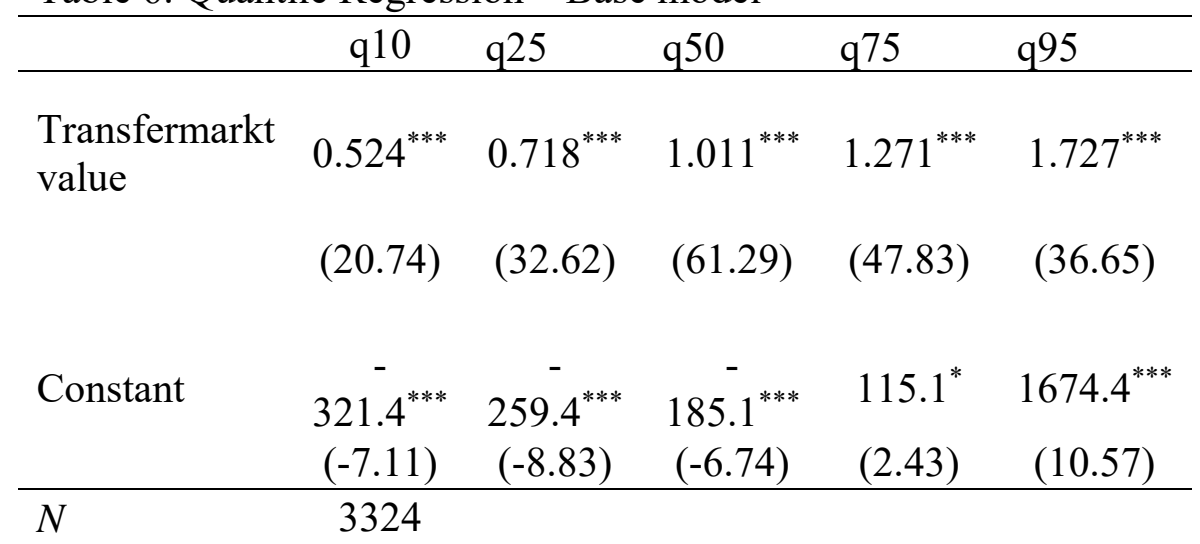

In each case, whether the base model of Table 6, the full model of Table 7 , or the full model restricted to the top leagues of Table 8 , the coefficient on the Transfermarkt value is far lower at the 10th percentile of the transfer fee distribution than at the $95^{\text {th }}$ percentile. At the $10^{\text {th }}$ percentile, the Transfermarkt

\footnotetext{
${ }^{5}$ Quantile regressions do not include the to and from country dummy variables as the model does not converge when they are included.
} 
value is a substantial over estimate of the actual fee paid, while at the $75^{\text {th }}$ and $95^{\text {th }}$ percentiles, the Transfermarkt values are substantial underestimates of the true fee paid. At the $50^{\text {th }}$ percentile, the median of the fees paid distribution, the Transfermarkt value coefficient is close to one. Results from the quantile regression model also reject Hypothesis 1, there are easily available variables whose inclusion in the model improves the ability to predict the actual transfer fee paid. Among these are having been on the National Team at some time before the transfer, the number of matches played, goals and assists per minute, and the player's age.

Table 7: Quantile Regression - FIFA

\begin{tabular}{|c|c|c|c|c|c|}
\hline & q10 & $\mathrm{q} 25$ & q50 & $\mathrm{q} 75$ & q95 \\
\hline $\begin{array}{l}\text { Transfermarkt } \\
\text { value }\end{array}$ & $\begin{array}{c}0.489^{* * *} \\
(9.76)\end{array}$ & $\begin{array}{l}0.709^{* * *} \\
(22.80)\end{array}$ & $\begin{array}{l}0.944^{* * *} \\
(28.21)\end{array}$ & $\begin{array}{l}1.209^{* * *} \\
(23.79)\end{array}$ & $\begin{array}{l}1.681^{* * *} \\
(17.45)\end{array}$ \\
\hline Matches & $\begin{array}{l}6.610^{*} \\
(2.15)\end{array}$ & $\begin{array}{c}8.734^{* * *} \\
(4.66)\end{array}$ & $\begin{array}{l}8.497^{*} \\
(2.54)\end{array}$ & $\begin{array}{l}8.543^{* *} \\
(2.60)\end{array}$ & $\begin{array}{c}43.30^{* * *} \\
(4.17)\end{array}$ \\
\hline Goals per minute & $\begin{array}{c}34203.3^{* *} \\
(2.68)\end{array}$ & $\begin{array}{c}43649.4^{* * *} \\
(4.58)\end{array}$ & $\begin{array}{c}47362.2^{* * *} \\
(3.48)\end{array}$ & $\begin{array}{c}73007.7^{* * *} \\
(5.63)\end{array}$ & $\begin{array}{c}113094.6 \\
(1.29)\end{array}$ \\
\hline Assists per minute & $\begin{array}{c}-22385.8 \\
(-1.33)\end{array}$ & $\begin{array}{c}-40011.7^{* *} \\
(-3.04)\end{array}$ & $\begin{array}{c}-44066.6^{*} \\
(-1.99)\end{array}$ & $\begin{array}{c}-27978.2 \\
(-0.80)\end{array}$ & $\begin{array}{c}-135971.8^{*} \\
(-2.06)\end{array}$ \\
\hline Age & $\begin{array}{l}205.0^{*} \\
(2.19)\end{array}$ & $\begin{array}{l}-102.7 \\
(-1.28)\end{array}$ & $\begin{array}{l}-350.2^{* *} \\
(-2.91)\end{array}$ & $\begin{array}{c}-999.6^{* * *} \\
(-5.80)\end{array}$ & $\begin{array}{c}-2444.2^{* * *} \\
(-4.08)\end{array}$ \\
\hline Age squared & $\begin{array}{l}-5.809^{* *} \\
(-2.93)\end{array}$ & $\begin{array}{c}0.0143 \\
(0.01)\end{array}$ & $\begin{array}{l}4.706^{*} \\
(1.98)\end{array}$ & $\begin{array}{c}16.47^{* * *} \\
(4.96)\end{array}$ & $\begin{array}{c}41.60^{* * *} \\
(3.77)\end{array}$ \\
\hline National Team & $\begin{array}{c}3039.8^{* * * *} \\
(4.20)\end{array}$ & $\begin{array}{c}2583.1^{* *} \\
(2.80)\end{array}$ & $\begin{array}{c}3510.9^{* * *} \\
(3.73)\end{array}$ & $\begin{array}{c}5073.6^{* *} \\
(2.75)\end{array}$ & $\begin{array}{c}3534.3 \\
(1.06)\end{array}$ \\
\hline $\begin{array}{l}\text { Transfermarkt } \\
\text { value*National } \\
\text { Team }\end{array}$ & $\begin{array}{l}0.124^{*} \\
(2.28)\end{array}$ & $\begin{array}{l}0.0723 \\
(1.48)\end{array}$ & $\begin{array}{l}0.124^{*} \\
(2.49)\end{array}$ & $\begin{array}{l}0.0931 \\
(1.38)\end{array}$ & $\begin{array}{l}-0.0718 \\
(-0.51)\end{array}$ \\
\hline FIFA rating & 3.701 & $10.12^{*}$ & $16.29^{* *}$ & $32.97^{* * *}$ & $58.50^{*}$ \\
\hline
\end{tabular}



(0.64)
(2.03)
(2.63)
(4.42)
(2.03)

FIFA

\begin{tabular}{lccccc}
$\begin{array}{l}\text { rating*National } \\
\text { Team }\end{array}$ & $-48.42^{* * *}$ & $-39.88^{* *}$ & $-54.83^{* * *}$ & $-77.18^{* *}$ & -45.06 \\
& $(-4.08)$ & $(-2.80)$ & $(-3.81)$ & $(-2.86)$ & $(-0.91)$ \\
Constant & & & & \\
& $-2187.6^{*}$ & 1361.8 & $4455.3^{* *}$ & $13068.6^{* * *}$ & $31656.3^{* * *}$ \\
& $(-2.01)$ & $(1.33)$ & $(2.98)$ & $(6.22)$ & $(3.83)$ \\
\hline$N$ & 3324 & & &
\end{tabular}

Table 8: Quantile Regression - Top leagues

\begin{tabular}{|c|c|c|c|c|c|}
\hline & q10 & q25 & $\mathrm{q} 50$ & $\mathrm{q} 75$ & q95 \\
\hline \multirow{2}{*}{$\begin{array}{l}\text { Transfermarkt } \\
\text { value }\end{array}$} & $0.517^{* * *}$ & $0.717^{* * *}$ & $0.929^{* * *}$ & $1.179^{* * *}$ & $1.594^{* * *}$ \\
\hline & $(7.32)$ & $(14.83)$ & $(14.36)$ & (11.91) & $(13.41)$ \\
\hline National Team & $\begin{array}{c}4463.0^{* *} \\
(3.15)\end{array}$ & $\begin{array}{c}4218.2^{* *} \\
(2.59)\end{array}$ & $\begin{array}{c}5704.8^{*} \\
(2.05)\end{array}$ & $\begin{array}{c}9667.7^{* * *} \\
(3.52)\end{array}$ & $\begin{array}{c}8307.9 \\
(1.62)\end{array}$ \\
\hline \multirow{2}{*}{$\begin{array}{l}\text { Transfermarkt } \\
\text { value*National } \\
\text { Team }\end{array}$} & 0.105 & 0.0757 & $0.160^{*}$ & 0.133 & -0.0614 \\
\hline & $(1.31)$ & $(1.23)$ & $(2.33)$ & $(1.31)$ & $(-0.46)$ \\
\hline \multirow[t]{2}{*}{ FIFA rating } & 18.27 & 23.95 & 16.7 & $48.72^{* *}$ & $100.7^{*}$ \\
\hline & $(1.00)$ & $(1.67)$ & $(1.08)$ & (3.16) & $(2.07)$ \\
\hline \multirow{2}{*}{$\begin{array}{l}\text { FIFA } \\
\text { rating*National } \\
\text { Team }\end{array}$} & $-66.19^{* *}$ & $-63.48^{* *}$ & $-87.53^{*}$ & $-142.1^{* * *}$ & -113.7 \\
\hline & $(-3.10)$ & $(-2.62)$ & $(-2.15)$ & $(-3.64)$ & $(-1.57)$ \\
\hline Matches & $\begin{array}{l}12.61^{*} \\
(2.16)\end{array}$ & $\begin{array}{l}17.06^{*} \\
(2.47)\end{array}$ & $\begin{array}{l}16.40^{*} \\
(2.36)\end{array}$ & $\begin{array}{l}18.55 \\
(1.95)\end{array}$ & $\begin{array}{l}55.91^{* *} \\
(3.23)\end{array}$ \\
\hline Goals per minute & $\begin{array}{c}64261.1^{*} \\
(2.45)\end{array}$ & $\begin{array}{c}79028.8^{* *} \\
(3.26)\end{array}$ & $\begin{array}{c}77458.7^{*} \\
(2.25)\end{array}$ & $\begin{array}{l}64700 \\
(1.29)\end{array}$ & $\begin{array}{c}196741.3 \\
(1.95)\end{array}$ \\
\hline
\end{tabular}




\begin{tabular}{lccccc} 
Assists per minute & -66553.8 & $-96860.3^{* * *}$ & $-95245.6^{*}$ & -108727.4 & -202837.5 \\
& $(-1.63)$ & $(-3.61)$ & $(-2.43)$ & $(-1.87)$ & $(-1.73)$ \\
& & & & & \\
Age & 74.83 & -213.4 & $-562.9^{* *}$ & $-1194.7^{* * *}$ & $-3289.3^{* * *}$ \\
& $(0.35)$ & $(-1.21)$ & $(-2.63)$ & $(-4.99)$ & $(-4.93)$ \\
& & & & & \\
Age squared & -4.174 & 1.435 & 8.07 & $18.93^{* * *}$ & $55.10^{* * *}$ \\
& $(-0.99)$ & $(0.40)$ & $(1.92)$ & $(4.00)$ & $(4.34)$ \\
Constant & -1127.5 & 2059 & $7556.6^{* *}$ & $15760.8^{* * *}$ & $41120.4^{* * *}$ \\
& $(-0.53)$ & $(0.85)$ & $(2.73)$ & $(4.50)$ & $(4.26)$ \\
\hline$N$ & 2242 & & & &
\end{tabular}


Figure 1: Marginal effects of Age at the $10^{\text {th }}$ and $95^{\text {th }}$ percentile of Fee paid - Full sample
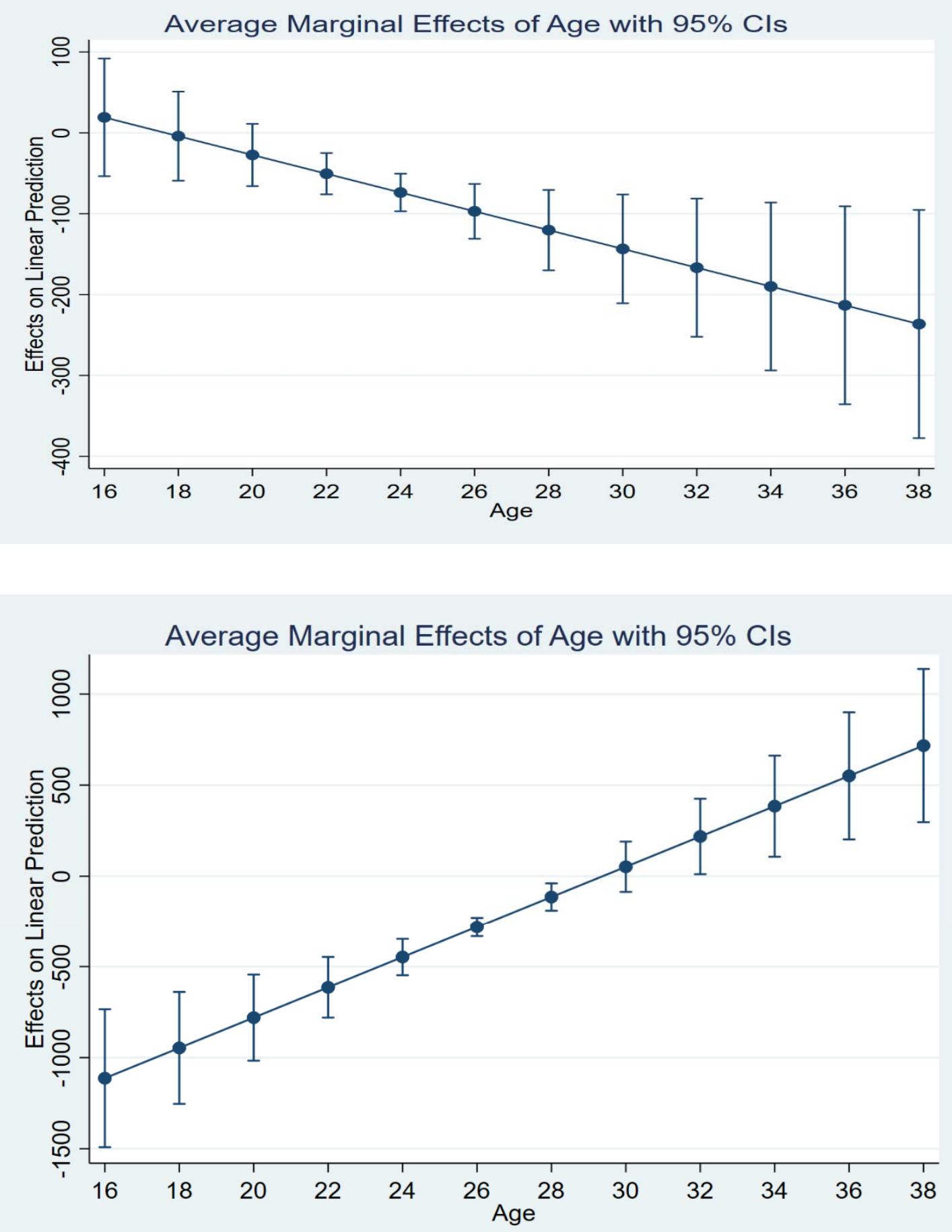
Figure 2: Marginal effects of Age at the $10^{\text {th }}$ and $95^{\text {th }}$ percentile of Fee paid - Top leagues
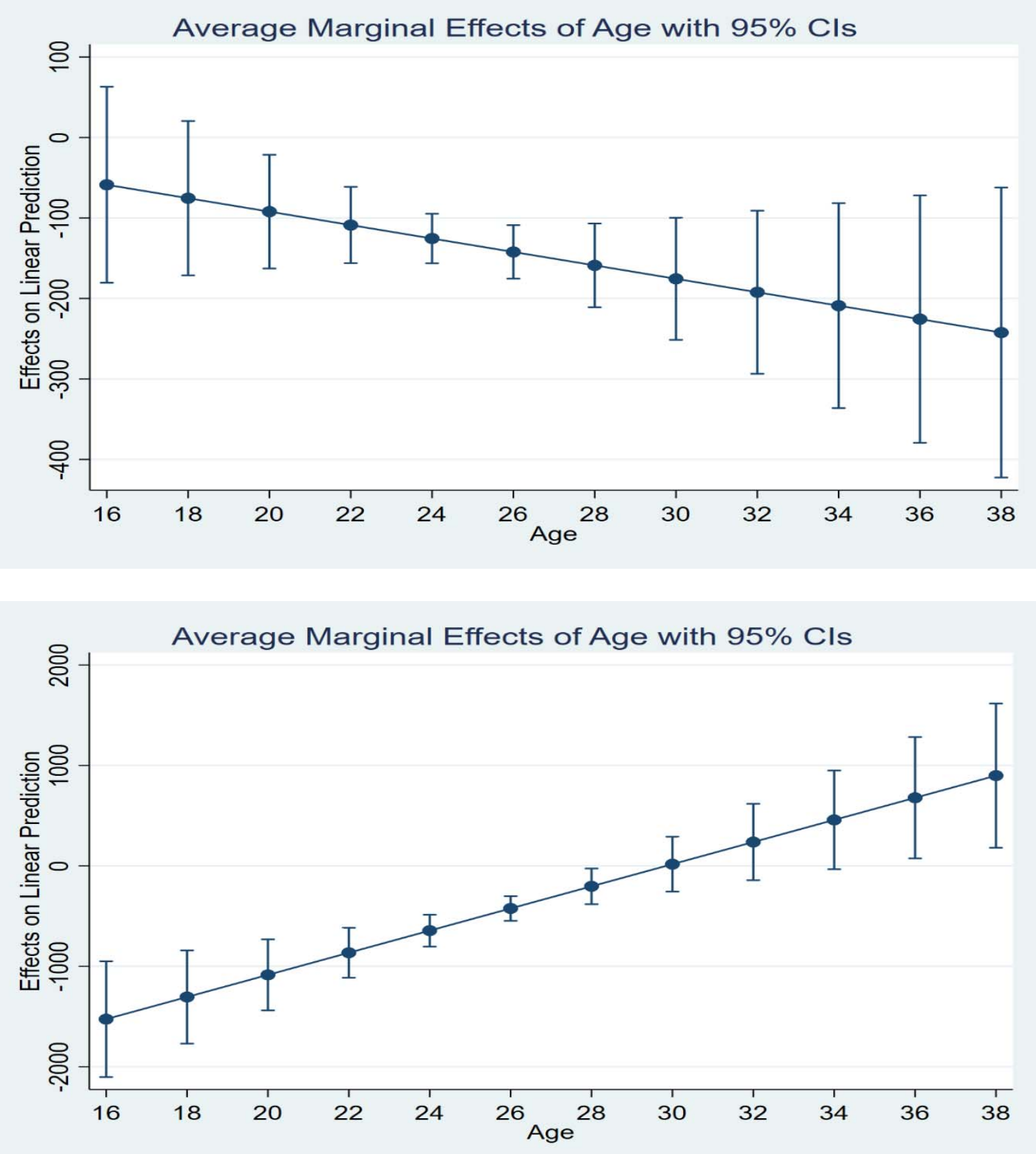

Interestingly, the relationship between the player's age and the fee paid varies depending on where in the fee paid distribution one looks. For example, in Table 7, which uses the full model but for all leagues, an increase in age, starting at very young ages, raises the fee paid but at a decreasing rate at the $10^{\text {th }}$ 
percentile of actual fees paid while at higher percentiles the effect of age falls at a decreasing rate. Of greater interest is the marginal effect of age within the relevant range of ages in the data, 16 years to 38 years. Figures 1 and 2 show the marginal effects of age starting from 16 years old up through 38 years old; Figure 1 is for the model of Table 7, Figure 2 is for the model of Table 8 . The upper panel in each is the marginal effect at the $10^{\text {th }}$ percentile of the fee paid distribution, the lower panel at the $95^{\text {th }}$ percentile. The figures make clear that at the low end of the fees paid distribution, aging by the player reduces the fee the club would pay, while at the high end of the fee distribution, a player getting older has a negative effect when they are very young, little effect when they are in their prime, and may have a positive effect as they get to the end of their careers. The difference between the full sample and the top leagues is one of degree, meaning that the size of the effects is larger in the top leagues than in the full sample, but the character of the effects is the same. Such findings also call in to question the approach to addressing player age of Müller et al. (2017), which included only the square of the players age, because it does not allow aging to affect value differently at a young age than at an older age.

As noted above, the data from EA Sports includes 35 attributes categories of football players evaluated for the FIFA soccer game. To this point, the analysis has only used the overall rating constructed from the attributes. Two types of quantile regressions introducing these variables have been estimated. The first type simply replaces the overall rating with the list of attributes though without the interaction with the National Team player dummy variable. The main finding of this type model is that the coefficient of the Transfermarkt value follows the same pattern as above, being less than one in the low quantiles but greater than one in the higher quantiles. The relationship of age to the fee is also similar to in the models above. The full list of attributes cannot reject the null of joint insignificance in these models. Detailed results will be available in an online appendix.

The second type of model explained the Transfermart value using the list of EA Sports attributes, goals and assists per minute, age and age squared, position dummies and the number of matches the player has participated in. In these models, the full list of attributes does reject the null hypothesis of joint insignificance. Among the individually significant attributes are heading accuracy, ball control and reactions. Strength, short passing, and vision are sometimes individually significant when the observations with missing values for goals and assists are included with zeroes replacing the missing values.

\section{Conclusion}

This paper sought to assess the accuracy of the transfermarkt.de crowd-sourced "market value" as a predictor of the true transfer fee for a player. The results indicate that the Transfermarkt value underestimates the worth of players with national team experience. Moreover, numerous widely available 
indicators of a player's skill or his career prospects are statistically significant including the Transfermarkt value. The upshot is that the crowd-sourced "market values" reported by Transfermarkt are a biased estimate of true value. To the extent that these values are used in contract negotiations between players and clubs or between clubs they present a misleading picture of the true value of a player.

For research that uses transfer fees as a proxy for actual fees or player salaries, our findings are a warning. Transfer fees used in place of salary are, by definition, variables measured with error. There are well-known econometric issues that arise from errors variables. Our results do not say that Transfermarkt or other crowd-sourced variables should not be used in regression analysis of football labor markets, but they do indicate that caution should be exercised when doing so.

More importantly, our quantile regression results make clear that the accuracy of the Transfermarkt values varies across the distribution of fees and between the top leagues and the lesser leagues. Moreover, the effects of a given variable on the actual fee for a player will differ quite a bit between the top leagues and those lesser leagues, particularly the second and lower division leagues. Players who have national team experience leading into a transfer, will be much more valuable than those without this experience.

There are, of course, questions raised by this research. For example, given that National Team experience affects value, to what extent does this effect depend upon the nature of that experience? Given the attributes that seem influence Transfermarkt value, are those specific skills compensated in player contracts and do the identified skills contribute to team success? This naturally leads to the Moneyball (Lewis, 2004) question of whether teams could improve their on-field success or their profitability by pursuing players with these undervalued skills.

\section{References}

Brown, A., \& Reade, J. J. (2019). The wisdom of amateur crowds: Evidence from an online community of sports tipsters. European Journal of Operational Research, 272(3), 10731081. edselp.

Bryson, A., Frick, B., \& Simmons, R. (2013). The Returns to Scarce Talent: Footedness and Player Remuneration in European Soccer. Journal of Sports Economics, 14(6), 606-628. https://doi.org/10.1177/1527002511435118 
Budescu, D. V., \& Chen, E. (2015). Identifying Expertise to Extract the Wisdom of Crowds. Management Science, 61(2), 267-280. ecn.

Carmichael, F., \& Thomas, D. (1993). Bargaining in the transfer market: Theory and evidence. Applied Economics, 25(12), 1467-1476. https://doi.org/10.1080/00036849300000150

Carmichael, Fiona, Forrest, D., \& Simmons, R. (1999). The Labour Market in Association Football: Who Gets Transferred and for How Much? Bulletin of Economic Research, 51(2), 125-150. https://doi.org/10.1111/1467-8586.00075

Davis-Stober, C. P., Budescu, D. V., Broomell, S. B., \& Dana, J. (2015). The Composition of Optimally Wise Crowds. Decision Analysis, 12(3), 130-143. ecn.

Dobson, S., Gerrard, B., \& Howe, S. (2000). The determination of transfer fees in English nonleague football. Applied Economics, 32(9), 1145-1152. buh.

Franck, E., \& Nuesch, S. (2012). Talent and/or Popularity: What Does It Take to Be a Superstar? Economic Inquiry, 50(1), 202-216. ecn.

Frick, B. (2007). The football players' labor market: Empirical evidence from the major European leagues. Scottish Journal of Political Economy, 54(3), 422-446. Scopus. https://doi.org/10.1111/j.1467-9485.2007.00423.x

Frick, Bernd, \& Wicker, P. (2016). Football experts versus sports economists: Whose forecasts are better? European Journal of Sport Science, 16(5), 603-608. https://doi.org/10.1080/17461391.2015.1119196

Haas, D. J., Kocher, M. G., \& Sutter, M. (2004). Measuring Efficiency of German Football Teams by Data Envelopment Analysis. Central European Journal of Operations Research, 12(3), 251-268. 
Herm, S., Callsen-Bracker, H.-M., \& Kreis, H. (2014). When the crowd evaluates soccer players' market values: Accuracy and evaluation attributes of an online community. Sport Management Review (Elsevier Science), 17(4), 484-492. sph.

Larrick, R. P., \& Soll, J. B. (2006). Intuitions About Combining Opinions: Misappreciation of the Averaging Principle. Management Science, 52(1), 111-127. buh.

Lewis, M. (2004). Moneyball: The Art of Winning an Unfair Game. W. W. Norton \& Company.

Mannes, A. E., Soll, J. B., \& Larrick, R. P. (2014). The wisdom of select crowds. Journal of Personality and Social Psychology, 107(2), 276-299. pdh. https://doi.org/10.1037/a0036677

Müller, O., Simons, A., \& Weinmann, M. (2017). Beyond crowd judgments: Data-driven estimation of market value in association football. European Journal of Operational Research, 263(2), 611-624. https://doi.org/10.1016/j.ejor.2017.05.005

P. J. Lamberson, \& Scott E. Page. (2012). Optimal Forecasting Groups. Management Science, 58(4), 805. edsjsr. https://doi.org/10.1287/mnsc.1110.1441

Peeters, T. (2018). Testing the Wisdom of Crowds in the field: Transfermarkt valuations and international soccer results. International Journal of Forecasting, 34(1), 17-29. buh.

Prockl, F., \& Frick, B. (2018). Information Precision in Online Communities: Player Valuations on www.Transfermarkt.De. International Journal of Sport Finance, 13(4), 319-335. sph.

Reilly, B., \& Witt, R. (1995). English league transfer prices: Is there a racial dimension? Applied Economics Letters, 2(7), 220-222. https://doi.org/10.1080/135048595357302

Speight, A., \& Thomas, D. (1997). Arbitrator Decision-Making in the Transfer Market: An Empirical Analysis. Scottish Journal of Political Economy, 44(2), 198-215. ecn. 
Surowiecki, J. (2004). The wisdom of crowds: Why the many are smarter than the few and how collective wisdom shapes business, economies, societies, and nations (1st ed). Doubleday.

Torgler, B., \& Schmidt, S. L. (2007). What shapes player performance in soccer? Empirical findings from a panel analysis. Applied Economics, 39(18), 2355-2369. https://doi.org/10.1080/00036840600660739

\section{Appendix}

Full Equations

$$
\begin{aligned}
& E\left[\left(\sum_{i}^{M} w_{i p} s_{i p}-V_{p}\right)^{2}\right]=E\left[\left(\sum_{i}^{M} w_{i p} s_{i p}\right)^{2}-2 V_{p} \sum_{i}^{M} w_{i p} s_{i p}+V_{p}^{2}\right] \\
& =E\left[\left(\sum_{i}^{M} w_{i p}\left(\mathrm{~V}_{p}+\delta_{\mathrm{ip}}+\varepsilon_{\mathrm{ip}}\right)\right)^{2}-2 V_{p} \sum_{i}^{M} w_{i p}\left(\mathrm{~V}_{p}+\delta_{\mathrm{ip}}+\varepsilon_{\mathrm{ip}}\right)+V_{p}^{2}\right] \\
& =E\left[\left(\sum_{i}^{M} w_{i p}\left(\mathrm{~V}_{p}+\delta_{\mathrm{ip}}+\varepsilon_{\mathrm{ip}}\right)\right)^{2}-2 V_{p} \sum_{i}^{M} w_{i p}\left(\delta_{\mathrm{ip}}+\varepsilon_{\mathrm{ip}}\right)-V_{p}^{2}\right] \\
& =E\left[\sum_{i}^{M} w_{i p}^{2}\left(V_{p}+\delta_{i p}+\varepsilon_{i p}\right)^{2}\right. \\
& +2 \sum_{i<j} \sum_{j}^{M} w_{i p} w_{j p}\left(\mathrm{~V}_{p}+\delta_{\mathrm{ip}}+\varepsilon_{\mathrm{ip}}\right)\left(\mathrm{V}_{p}+\delta_{\mathrm{jp}}+\varepsilon_{\mathrm{jp}}\right)-2 V_{p} \sum_{i}^{M} w_{i p}\left(\delta_{\mathrm{ip}}+\varepsilon_{\mathrm{ip}}\right) \\
& \left.-V_{p}^{2}\right]
\end{aligned}
$$

